\title{
¿Y educar para qué? Representaciones mediáticas de narcocultura en los modelos del progreso económico y prestigio social ${ }^{*}$
}

\author{
JAIME WILCHES TINJACÁ**
}

\author{
Artículo recibido: 10 de enero de 2014 \\ Artículo aprobado: 20 de marzo de 2014 \\ Doi: dx.doi.org/10.12804/desafios26.1.2014.06
}

Para citar este artículo: Wilches Tinjacá, J. (2014). ¿Y educar para qué? Representaciones mediáticas de narcocultura en los modelos del progreso económico y prestigio social. Desafíos, 26 (1), 199-234. doi: dx.doi.org/10.12804/desafios26.1.2014.06

\section{Resumen}

El texto propone un debate sobre las limitaciones de los modelos educativos para dar cuenta de las realidades que enfrentan las y los estudiantes, en especial, en zonas del país donde el narcotráfico ha inspirado estilos de vida riesgosos, pero legítimos, para sobreviviry lograr reconocimiento social (narcocultura). El problema es más complejo: el modus operandi de la narcocultura ha posicionado sus relatos en los canales privados de televisión, los cuales normalizan el imaginario de "ser alguien en la vida" como un asunto que se puede lograr sin necesidad de años de esfuerzo en una escuela (lejana y ajena a la sociedad). Se llama la atención sobre la urgencia de reconstruir algunos de los supuestos sobre los que está fundada la apuesta de la educación y cómo esta debe

\footnotetext{
* El artículo forma parte del proceso de investigación realizado en el proyecto "Narcocultura y ficción televisiva", financiado por la Dirección de Investigaciones de la Universidad Nacional de Colombia, sede Bogotá.

** Docente e investigador del programa de Negocios y Relaciones Internacionales, de la Universidad de La Salle, Bogotá. Correo electrónico: jawilches@unisalle.edu.co
} 
motivar a sus estudiantes a verla como un medio para formar ciudadanía y no como un fin para alcanzar el progreso económico y el prestigio social.

Palabras clave: educación, modernidad, narcocultura, progreso económico, ficción televisiva

\title{
Education for What? Media Representation of Narcoculture in Models of Economic Progress and Social Prestige
}

\begin{abstract}
The article proposes a discussion of the limitations of educational models to account for the realities faced by students in areas where drugtrafficking has gone from being an illegal business to a risky life style, while being considered legitimate for survival and in order to achieve social recognition (narcoculture). The problem, however, is even more complex: the modus operandi of the narcoculture has been successful in positioning its stories in private television networks. In turn, these networks normalize the idea of becoming someone in life as something that can be achieved without spending years of efforts in a (distant and alien to society) school. In this regard, the article draws attention to the urgent need to rebuild some of the assumptions on which education is based and how it should motivate students to see school as a means to form citizens, not as an end to desperately look for economic progress and social prestige.
\end{abstract}

Key words: education, modernity, narcoculture, economic progress, television fiction E educar para que? Impactos das
representações mediáticas da narcocultura
na orientação dos modelos do progresso
econômico e o prestigio social

Resumo

O texto propõe um debate sobre as limitações dos modelos educativos para dar conta das realidades que enfrentam os estudantes, em especial, em zonas do país onde o narcotráfico tem conseguido ser um negócio ilegal que inspira estilos de vida arriscados, 
mas legitimos para sobreviver e alcancar reconhecimento social (Narco Cultura). O problema, no entanto, é mais complexo: o modus operandi da Narco Cultura tem conseguido efetividade em posicionar seus relatos nos canais privados de televisão, os quais normalizam o imaginário de Ser alguém na vida como um assunto que se pode alcançar sem necessidade de empreender anos de esforços em uma escola (distante e alheia à sociedade). Neste sentido, chama-se a atenção sobre a urgência de reconstruir alguns dos supostos sobre os quais está fundamentada a aposta da educação, e como ela deve motivar a seus estudantes a ver a escola como um meio para formar cidadania, e não como um fim para procurar de forma desesperada o progresso econômico e oprestigio social.

Palavras- chave: Educação, Modernidade, Narco Cultura, Progresso Econômico, Fiç̧ão Televisiva

Aunque pareciera obvio, no sobra señalar que el mundo occidental construyó entre los siglos XVI y XVIII sus modelos políticos, económicos y culturales en el proyecto de la modernidad, cuyos pilares se fundamentaron en la libertad del individuo, el respeto a las leyes escritas por los hombres y la razón científica.

No obstante, cuando se suele hacer referencia a la promesa de la modernidad se presenta una paradoja: por un lado, muestra una visión que predicaba la libertad como un principio fundamental de los seres humanos, añorada después de tantas guerras y sumisión al poder divino y se ve la luz del conocimiento y del hombre como artífice de su destino; de otra parte, una perspectiva que piensa dicha libertad con un orden que privilegia el individualismo, la competencia y el cambio del dios cristiano por el dios del mercado.

En esta dirección, una de las invenciones sociales más efectivas, pero más problemáticas, llega con la creación de instituciones que se encargaron de controlar, disciplinar, administrar, vigilar y supervisar la aceptación de las reglas de juego por parte de individuos y colectivos (Foucault, 2001; 2009) o lo que Patiño (2006) denomina coerción capitalizada, es decir, un fenómeno que, si bien tiene en cuenta la euforia 
desatada por los sentimientos de la revolución, se sostuvo gracias al éxito de los precursores de la idea de Estado moderno al momento de controlar los recursos de la violencia armada y del naciente modelo capitalista.

Así pues, comienza un complejo proceso de transformación en el que se cruzan distintas visiones de los pilares de la modernidad y de los usos y fines que deberían tener las formas de organización social. Por ejemplo, la división de poderes (Ejecutivo, Legislativo y Judicial), en principio pensado para la independencia de las funciones de cada uno de sus órganos y en procura del bienestar social, se vio afectada por distintos sectores que tienen poder e influencia política y económica para corromper tal separación, si es que esto convenía a la satisfacción de sus intereses.

En el caso que compete a los propósitos de este artículo, otra de las paradojas de la modernidad se representan en la figura de la escuela, pues sus propósitos se debaten entre la idea de formar ciudadanos y sujetos críticos de sus realidades y una lógica económica e instrumental: formar trabajadores que deben capacitarse para cumplir con las demandas del mercado empresarial (Morin, 1984).

A pesar de los esfuerzos y las advertencias de distintas corrientes pedagógicas por tender puentes para que las dos perspectivas entablaran diálogos vinculantes y horizontales (Buenaventura, 1995), el economicismo terminó imponiéndose sin tener en cuenta las variables socioculturales e históricas que el modelo debía pensar antes de implementarse en nombre de la eficiencia y con sacrificio de la subjetividad y las necesidades del contexto en donde se implementaron.

No es de extrañar que la inclinación paulatina por ver a los estudiantes como objetos para capacitar antes que como sujetos para pensar tuviera influencia en los empresarios que empezaron a financiar las primeras instituciones educativas, inclinadas a formar obreros para las grandes industrias (Costa y Domenech, 2002, p. 35). Esto no quiere decir que formar para el trabajo no sea una práctica válida, pero sí se puede cuestionar un estilo de educación que abandonó el diálogo 
entre individuos, para darle paso al miedo entre individuos (Buenaventura, 1995).

En otras palabras, otorgó importancia a una educación de tres cortes: el primero, con un estilo militar y autoritario, inspirado en el modelo prusiano de los siglos XVIII y XIX (De Vroede, 1989), donde el maestro produce más miedo que respeto y contradice de manera explícita los valores de la igualdad, la libertad y la fraternidad pregonados desde las revoluciones burguesas (La educación prohibida, 2012); el segundo, con la razón científica de espalda a las guerras y los regímenes totalitarios como el nazismo (Horkheimer, 1983) y el tercero, con un sistema excluyente donde se funda la idea de sociedades civilizadas y otras de "tercer mundo", que deben ser educadas en los modelos racionales con desconocimiento del impacto social que estos puedan tener en individuos y colectivos que conciben su formación en escenarios distintos a la escuela moderna (Castro Gómez, 2000).

El caso colombiano no escapa a esta breve contextualización; por el contrario, se complejiza, pues además de compartir las constantes históricas expuestas, arrastra con un modelo educativo que tiene tareas pendientes por resolver - docentes mal remunerados, estructuras curriculares improvisadas e instalaciones en mal estado, entre otros factores- (Vasco, 2006). A eso se suma el bajo presupuesto que asigna el Estado al sector, la formulación de políticas públicas en favor de los intereses o caprichos del Gobierno de turno y el liderazgo exiguo de buena parte de los ministros de Educación, que casi siempre ocupan un lugar secundario en el gabinete ministerial o tienen poca incidencia en la formulación de las políticas educativas que se debaten en el plano internacional (Cajiao, 2004).

Aunado a ello, surgen dos situaciones particulares: la primera, la revolución de los medios masivos y alternativos de comunicación que, gracias a los avances tecnológicos, se han convertido no solo en los nuevos organizadores de la opinión pública, sino en el lugar que la escuela ha descuidado, para orientar modelos de comprensión de las experiencias que afrontan los ciudadanos en su vida cotidiana. La investigación sobre cultura política en Colombia (Rodríguez-Raga y 
Seligson, 2007) retrata parte de esta situación, al afirmar que una buena porción de los colombianos construyen sus referentes de la realidad de acuerdo con la información presentada en televisión, radio y prensa.

El segundo fenómeno es la aparición del narcotráfico a manera de modelo que desbordó el marco económico del prohibicionismo para inspirar estilos de vida ilegales, pero legitimados por amplios sectores de la sociedad colombiana, que lo asumen como una forma de progresar con rapidez y efectividad, aunque con riesgo y a corto plazo. En razón a lo expuesto, se pretende ir más allá de los juicios condenatorios al modelo educativo colombiano, para llamar la atención sobre la necesidad de desplazarse, así sea por un instante, de las recomendaciones dictadas por las instituciones internacionales o las presiones de un modelo económico globalizado, para construir modelos pedagógicos que se relacionen de modo más directo y atractivo con los ciudadanos, contrario a la verticalidad profesor-estudiante y la obsesión por el cumplimiento de currículos y contenidos.

Esta propuesta apunta a hacer frente al desplazamiento de la educación formal en favor de representaciones sociales que validan la visión predicada por la narcocultura y reforzada en los medios masivos de comunicación y que se explica en el planteamiento que se resalta a continuación:

Las razones construidas por los libretistas apuntan a problematizar la legitimidad del narcotráfico ante la imposibilidad de la educación — entendida y dirigida para satisfacer las demandas de los jóvenes - en el momento de responder a las expectativas y sueños plasmados por un mundo donde dicho progreso parece estar más relacionado con la adquisición de bienes materiales y más alejado de la formación de seres humanos con sentido y reconocimiento de una ética civil.

En otras palabras, los seriados presentan un relato ficcionado desde la ilegalidad del negocio, con el objeto de no enfrentar a las instituciones que desde la legalidad podrían sentirse incómodas con este tipo de narrativas. 
Sin embargo, las fallas del modelo legal para satisfacer las demandas de las personas que intentan acceder a las oportunidades que les aseguren un bienestar individual y familiar, ofrecen un amplio margen para que, desde las representaciones de situaciones cotidianas y sectores excluidos, se presente al narcotráfico como un camino que ofrece alternativas riesgosas, pero válidas, para ascender y gozar de prestigio social. ${ }^{1}$

Para sustentar los párrafos anteriores, el artículo se divide en cuatro partes. En la primera, se recorren las dinámicas que originaron la instauración de la educación como proyecto cultural de la modernidad y las críticas que dicho modelo recibió por parte de Gadamer, Montessori, Vygotsky, Freire y Nussbaum. Luego se muestra el contexto que posibilitó la transformación del narcotráfico de modelo ilegal a un estilo de vida que trasgrede los paradigmas convencionales de la educación como institución garante del progreso económico y en una sección posterior se describe la forma como los productores de ficciones televisivas aprovecharon esta coyuntura, para legitimar el narcotráfico como una opción social ante las carencias de las instituciones educativas. Por último se ofrecen unas consideraciones finales.

\section{Educación para la de-formación}

La bibliografía y las voces referentes a los orígenes de la institucionalización de la educación han crecido en los últimos años, lo que se traduce en interés y preocupación de un sector de académicos e investigadores por el rol social de la educación y su impacto en la cotidianidad de individuos y colectivos. Puede decirse que uno de los referentes más impactantes ha surgido después de la presentación del documental La educación probibida (Doin, 2012).

El audiovisual presenta de manera contundente la forma como la Ilustración y las revoluciones burguesas fueron pensadas con el ánimo de generar una masa de trabajadores capacitados para los nuevos desafíos de la industrialización. Los productores del audiovisual argumentan

\footnotetext{
1 Este texto pertenece a una reflexión personal del autor, resultado del proceso de investigación.
} 
entre líneas cómo se pasa de los gritos que proclamaban la libertad a los regaños de los maestros; de la arbitrariedad del rey al autoritarismo de las directivas de instituciones educativas; de las consignas que defendían el descubrimiento de nuevos mundos al control de la creatividad de niños, jóvenes y adultos.

Así pues, muchos individuos terminaron estandarizados en un cúmulo de conocimientos que se adquirían para obtener un título que los capacitara para desempeñarse en el mundo laboral. El impulso de los descubrimientos científicos parecían darle la razón al modelo pedagógico basado en el control para el progreso racional y el desarrollo económico, como el camino indicado para que los seres humanos fueran civilizados y vivieran, tal vez, inspirados en la paz perpetua que pensaba Kant.

El nazismo relativiza esta idea y demuestra que, pese a la fuerza del autoritarismo de su poder armado, se puede llegar a grados extremos de barbarie con la complicidad explícita o silenciosa de sectores educados de la sociedad, los cuales tendrían un papel preponderante en la Alemania de Hittler y pondrían al desnudo las debilidades del concepto de civilización. El texto de Viktor Frankl (s. f.) es contundente cuando señala los excesos del nazismo:

Pero más que todos aquellos horrores me impresionó algo que por aquellos días leí, escrito por una antigua residente del campo, maestra de escuela. Comentaba que aquellas cámaras de gas habían sido construidas por ingenieros especialistas. Que las inyecciones letales las ponían médicos o enfermeros titulados. Que niños recién nacidos eran asfixiados por asistentes sanitarias competentísimas. Que mujeres y niños habían sido fusilados por gentes con estudios, por doctores y licenciados. Y concluía: "Desde que me di cuenta de esto, sospecho de la educación que estamos impartiendo".

Las observaciones frente a un régimen que todos juzgaban por su atrocidad, pero toleraban por complicidad, generaron propuestas bienintencionadas de teóricos que criticaron el modelo de instrucción, no solo desde el nazismo, sino desde el mundo liberal moderno. Debido a esto, comenzaron a dar relevancia a la formación de ciudadanos éti- 
cos, honestos y comprometidos, antes que a estudiantes, trabajadores y profesionales.

Gadamer sería uno de los teóricos más destacados en señalar la importancia de la "formación sustentada en el pensamiento", antes que de la educación basada en instrucciones. Según la lectura de Ríos (2010), para Gadamer

[...] el resultado de la formación no se produce al modo de los objetos técnicos, sino que surge del proceso interior de la formación y conformación y se encuentra por ello en un constante desarrollo y progresión. Para Gadamer, esta nueva significación no permite ya hablar en términos de "objetivo de la formación", pues si la formación es un proceso en constante estado de desarrollo y progresión, "no puede ser un verdadero objetivo; ella no puede ser querida como tal si no es en la temática reflexiva del educador, [ya que] el concepto de la formación va más allá del mero cultivo de capacidades previas", apunta a algo que está más allá de la habilidad y la destreza y, por tanto, del desarrollo de capacidades o talentos (p. 18).

La Ilustración consolida la idea de las ciencias empíricas naturales como ejes de comprensión para entender la realidad. Gadamer comprende que, independiente de las intenciones de este propósito, las ciencias catalogadas como "científicas" son útiles para definir leyes de la naturaleza, pero tal vez puedan ser limitadas para comprender los modos de vivir y pensar de las sociedades.

En este punto de quiebre está la pregunta ¿para qué se conoce? Gadamer se apoya en Hegel (Sopó, 2007) para plantear la necesidad de distanciarse del concepto de formación como una técnica para aprender a hacer algo — técnica que termina imponiéndose en los modelos educativos y en los que nos preocupamos más por la utilización de los conceptos, que por su comprensión- (Ríos, 2010, pp. 22-24).

Las inquietudes planteadas por Gadamer inspiraron variados y debatidos modelos pedagógicos alternativos. Es el caso de Montessori, 
quien crítica el sistema de los premios y castigos; influenciada por sus conocimientos de medicina y de la teoría darwiniana promueve una educación que observe y diagnostique las particularidades de cada niño, con el fin de trabajar de manera individual en su proceso de formación. Según Chavarría (2012) este modelo resulta inspirador porque:

Para la niñez, somos mucho más que educadoras: representamos un ejemplo de lo que la cultura cree que es la educación, que en el mundo occidental implica conocimientos mentalistas y descontextuados y obligatorios, fundamentados en un sistema simbólico predominantemente verbal (Álvarez, 1990). También somos un indicador de lo que no se puede hacer en el sistema educativo: rápido se aprende que no se puede ser espontáneos ni creativos, ni gozosos, ni únicos. A la vez, que se debe ejercer un esfuerzo mínimo y ser lo suficientemente sumisos para que la cultura escolar no se convierta en una pesadilla (véase el interesante análisis de del Río y Álvarez, 1992, desde una perspectiva histórico-cultural). Somos representantes de las contradicciones culturales, como la obligatoriedad de un sistema escolar que es visto como verdadero pero no relevante. Omitir verlas se convierte en nuestro talón de Aquiles; de ahí lo crucial de desentrañar las corrientes culturales que tendemos a invisibilizar (p. 29).

Desde otra perspectiva, Vygotsky apela por una pedagogía de corte sociocultural que, a diferencia del método montessoriano, evita la individualización de las actividades en el aula de clase, para fomentar una pedagogía que salga de ella y experimente con el entorno cotidiano. De acuerdo con la interpretación de Martínez (1999), Vygotsky pretende salir de los cánones de la biología en el momento de explicar los comportamientos de los sujetos en la escuela:

Desde la perspectiva del enfoque sociohistórico o sociocultural, Vygotsky introdujo un concepto de gran trascendencia para explicar las diferencias entre el nivel de desarrollo real y el nivel de desarrollo potencial del niño. Me refiero al concepto de zona de desarrollo próximo (ZDP), el cual ha resultado muy útil para explicar las diferencias en el aprendizaje y en el desarrollo intelec- 
tual entre individuos que, siendo de la misma edad cronológica, muestran conocimientos y habilidades superiores a las de otros compañeros. En la demarcación de esta zona se puede notar la interacción de dos de los planos genéticos en los que Vygotsky ubicaba su argumentación: el dominio ontogenético y el plano sociohistórico. Esta zona corresponde a ese punto donde la cultura y la cognición interaccionan y se crean mutuamente (Cole, 1985), esto es, donde los procesos sociales y culturales que se ponen en funcionamiento en la escuela y el desarrollo cognitivo del sujeto se encuentran (p. 30).

En otra orilla, menos preocupada por las dimensiones biológicas del niño, se encuentra Paulo Freire, quien asume una postura crítica frente a la imposición de la educación como un sistema excluyente que forma para el elitismo económico. Esta perspectiva tuvo amplia recepción en América Latina, por tratarse de un modelo que abogaba por una escuela popular y pertinente para los menos favorecidos. En palabras de Brito (2008):

Esta problemática nos lleva a reflexionar acerca del déficit de las políticas educacionales en la región y su impacto en la función y efectividad de la educación como derecho pleno del hombre. Las nuevas políticas y agendas educacionales que hoy emergen demandan un programa educativo integral comprometido con el cambio, que parta de una educación abierta, responsable, crítica. Para la pedagogía actual resulta necesario, además, incentivar aprendizajes creativos, transformadores e innovadores, que son clave en una formación integral ante las demandas profesionales que exige la vida contemporánea, completamente informatizada, globalizada y capitalizada (p. 30).

Pese a las interesantes posturas de los modelos descritos y la buena cantidad de recursos bibliográficos y de revistas científicas dedicadas a analizar los retos y los desafíos de la educación, los modelos propuestos han sido criticados de manera injusta por ser exclusivos o difíciles de implementar debido a la gran cantidad de estudiantes que se debe atender. Surgen preguntas que cuestionan la posibilidad del método 
Montessori en un aula de más de treinta estudiantes o la idealización de Vygotsky cuando el maestro debe estar más atento a los currículos que a los orígenes culturales de sus educandos y, en el peor de los casos, las limitaciones de la educación popular, donde poco sirve ser buen ciudadano si se vive en condiciones de pobreza extrema.

Por supuesto, la meta de hacer dinero con la instrucción de conceptos fue impuesta sobre la de formar ciudadanos para el intercambio de ideas, en un mundo en el que se fue consolidando la representación social del progreso económico como mecanismo de reconocimiento y admiración, en detrimento de la formación de una esfera pública apática e indiferente hacia la construcción de la democracia como un asunto que debe articular la representación con la participación. Nussbaum (2010) hace una de las críticas más fuertes a esta dinámica mercantilizadora:

Sin embargo, los especialistas en educación para el crecimiento económico no se limitan a hacer caso omiso de las disciplinas artísticas y humanísticas. En realidad, les tienen miedo, pues el cultivo y el desarrollo de la comprensión resultan especialmente peligrosos frente a la moral obtusa, que a su vez es necesaria para poner en práctica los planes de crecimiento económico que ignoran la desigualdad. Resulta más fácil tratar a las personas como objetos aptos para ser manipulados si uno nunca aprendió a verlas de otra manera. En palabras de Tagore, el nacionalismo agresivo necesita embotar la conciencia moral y, en consecuencia, necesita personas que no reconozcan lo individual, que hablen una jerga grupal, que se comporten como burócratas dóciles y que también vean el mundo como tales. El arte es un gran enemigo de ese carácter obtuso (p. 46).

Hay que tener en cuenta que uno de los factores para esta imposición fue la incapacidad del Estado para atender a los nuevos retos de la pedagogía y dejó la administración de la formación en manos de los privados. Esto implica un cambio en la visión de la educación, pese a las buenas intenciones de presentarse como instituciones sin ánimo de lucro, pues esto también significa sin ánimo de pérdida. La orientación 
de este modelo también ha significado ampliar la brecha de desigualdad, la centralización de las instituciones en Bogotá y el acceso a la educación superior de 25 a 35\% de los bachilleres - los que tienen recursos acceden a costosos créditos bancarios o son financiados por el Icetex- (Ministerio de Educación Nacional, 2012).

De esta manera, el modelo genera procesos de exclusión y búsqueda desesperada por parte de individuos temerosos de quedar por fuera de la oferta de oportunidades y articulados, sin posibilidad de hacer preguntas, a la visión de un mercado que valida el egoísmo y la satisfacción de necesidades sin importar las reglas de la ética; ahí lo que en realidad vale son las reglas autorreguladas del mercado (Friedman, 1992).

¿Cómo impacta esta concepción de la educación en Colombia? No se pretenden respuestas causalistas u omnicomprensivas, pero después del proceso investigativo se pueden esbozar algunas interpretaciones que, contrario a cerrar el debate, buscan abrir espacios de discusión entre los actores de las instituciones educativas (estudiantes, padres de familia, docentes, directivos, grupos de interés).

\section{En la apatía de la institución educativa, el oportunismo de la narcocultura}

Las situaciones descritas en la sección anterior pueden ser interpretadas en distintos contextos que viven una crisis de los conceptos de legalidad y legitimidad del Estado. Colombia y su situación de país tercermundista no escapan a esta realidad, que es aún más profunda si se tiene en cuenta que los principios fundacionales de la modernidad no tuvieron el anclaje esperado en la formación del Estado-Nación. En realidad, el país nunca tuvo un proyecto de modernidad consistente y acorde con sus realidades; más bien, fue un proceso improvisado, incoherente y mal copiado de Europa y Estados Unidos (Jaramillo, 1998), en el peor de los casos, centralista, excluyente e indiferente a la pluralidad sociocultural de sus ciudadanas y ciudadanos (Múnera, 2008).

En este sentido, se avanza (¿se retrocede?) en un legalismo que sería visto como una impecable pieza gramatical, pero con profundos va- 
cíos en su anclaje a las realidades de las múltiples colombias (Uribe, 1992) y con una legitimidad negociada desde el intercambio de favores - clientelismo- (Jaramillo, 2006), la negociación y captura del Estado — corrupción- (Garay, 2008), la disputa del poder político por las buenas o por las malas — democracia con violencia- (Palacios, 2003) y el amplio espacio para que los grupos ilegales sustentaran las necesidades de sectores olvidados por el aparato estatal (Duncan, 2006; Pizarro, 2011).

En esta situación surgió otro camino: algunos optaron por reconstruir su vida cotidiana y validaron las ofertas que les posibilitara solucionar sus necesidades inmediatas y dejaron en un segundo plano el origen moral o inmoral, justo o injusto, bueno o malo de dicho catálogo de oportunidades para el progreso económico. Allí está el caso del contrabando en La Guajira y la instauración de reglas de juego que difieren de las disposiciones jurídicas, pero que son interiorizadas por la comunidad en una espiral de motivaciones compleja de descifrar. Tales reglas tienen un péndulo que va de la amenaza a la conveniencia y pasan por la inevitabilidad, ante la ausencia de opciones (Orsini, 2007).

Entre el catálogo de oportunidades ilegales, pero válidas, aparece el narcotráfico. Aquí vale la pena precisar que no se está diciendo que es la única respuesta a una sociedad excluyente; lo que se quiere sustentar es que este modelo de vida aparece dentro del difuso abanico de opciones para enfrentar las necesidades de la vida cotidiana. Unos optaron por el trabajo — en su mayoría mal remunerado por las empresas legales (Sennett, 2000) — y para otros apareció el mundo narcomafioso como alternativa, no absoluta, pero sí rentable y cada vez más compleja de identificar en relación con sus estructuras, redes y formas de organización (Gambetta, 2007).

En otras palabras, el narcotráfico parece haber logrado su supervivencia y adaptación en razón a la miopía institucional. Esta insiste de manera terca e ingenua en mirarlo como un fenómeno ilegal que basa su fuerza en su rentabilidad económica y que se soluciona con medidas prohibicioncitas, presionadas por los países que consumen este tipo de productos (Thoumi, 2002). 
Lo que se ignora, con o sin intención, es la fuerza multidimensional del narcotráfico como una empresa que se instala en el repudio predecible de las políticas públicas y de la ilegalidad económica (Vargas, 1999). Todo esto resulta una respuesta válida ante un Estado que se presenta como una amenaza o como un órgano ausente, indiferente e incapaz de responder a los retos de una historia mediada por odios, resentimientos y escepticismos (González, Bolívar y Vásquez, 2002).

Una de esas respuestas a las que el narcotráfico ha dado trámite está relacionada con la idea del progreso económico, el cual sustenta el consumo de bienes como una de las reglas para sobrevivir en el mercado. Atrás quedaron las concepciones de lo público, la ciudadanía y la ética, para construir unas representaciones sociales concretas en la que se exacerban los valores más tradicionales de la sociedad colombiana (individualismo, protección a los integrantes más cercanos de la familia, irrespeto por la vida, apatía por lo público, respetar la ley según la situación, entre otras). Ovalle y Giacomello (2006, p. 299, citado en Quiñones, 2011) refuerzan este argumento cuando plantean:

$[\ldots]$ las fronteras entre la "narcocultura" y las culturas oficiales se presentan bastantes borrosas [...]. El derroche, la opulencia, la transgresión, el incumplimiento de la norma y el machismo son, entre otras, prácticas sociales continuamente asociadas al "narcomundo"; sin embargo, vemos que todas ellas son en mayor o menor medida prácticas recurrentes en las culturas oficiales (p. 73).

La indiferenciación de la cultura "legal" del statu quo con la "ilegal" del narcotráfico va recorriendo distintos espacios sociales, hasta interiorizarse en el sentido común de los individuos. Quiñones (2011), en su investigación sobre la representación de la mujer en las narcoseries, advierte que la etapa del negocio como una empresa criminal es apenas una de las aristas de un modo de vida que ha llegado a definir hasta el papel de las mujeres, con la complicidad de las estructuras institucionales:

Distintos autores coinciden en la consideración del "narcomundo" como un sistema esencialmente machista, donde se reproduce en 
forma caricaturesca el "orden" social instaurado artificialmente sobre la base del supuesto de la superioridad masculina. Por lo tanto, es común que en el mundo del narcotráfico se construyan relaciones de género a partir de un conjunto de actitudes y comportamientos que discriminan y marginan a la mujer por su sexo (informes de observación) (p. 73).

En este punto, vale la pena cuestionarse sobre el papel de las instituciones políticas, económicas y sociales para contener los alcances del narcotráfico en la configuración de nuestro ethos. La respuesta más sencilla parece estar en la educación como antídoto para prevenir a las nuevas generaciones de caer en un mundo peligroso y azaroso, en aras de obtener cosas por vía del trabajo honrado y constante.

Pero esta premisa se cae de su peso cuando se tiene un sistema educativo precario en cuanto a oportunidades de acceso a la universidad, que en los niveles de primaria y secundaria ha impuesto la cobertura sobre la calidad, al amontonar estudiantes en aulas de clase y que establece diferencias entre la educación que deben recibir los ricos (privada, con maestros bien remunerados, instalaciones y recursos de primera clase) y los pobres (pública, maestros desmotivados y presupuestos irrisorios), lo que en palabras de García y Quiroz (2011) ha conformado un apartheid educativo:

En Colombia, no solo tenemos un sistema educativo que ofrece niveles de calidad diferenciales según la clase social, sino que este impone, de hecho, una especie de apartheid educativo: los ricos estudian con los ricos y los pobres con los pobres.

El apartheid educativo viola la regla de oro de la democracia liberal (y peor si se trata de la democracia social): la igualdad de oportunidades. Las normas jurídicas consagran la igualdad de oportunidades, pero ese objetivo se desvanece en el entramado institucional y social del sistema educativo [...]. El capital cultural está tan mal repartido en nuestra sociedad como el capital económico, y aún peor, ambos se concentran y escasean en las mismas personas. Una educación socialmente segregada, es decir, que funciona en 
un contexto de apartheid social, castiga con bajos niveles de capital cultural a gran parte de la población y desfavorece la movilidad social (pp. 158-159).

Así, la educación pierde sentido en la medida en que va siendo concebida como un escalón innecesario, incómodo o incongruente con una realidad donde el dinero vale más que las personas. Se puede enseñar valores, sentimientos y proyectos de Nación, pero estos se olvidan cuando el estudiante encuentra que las buenas intenciones de algunos profesores son borradas por el afán de sobresalir en un ambiente de oportunidades laborales escasas y en una competencia esquizofrénica con otros individuos con las mismas historias de exclusión. La reflexión de Ospina (2010) es más que pertinente:

¿Cómo superar una época en la que la educación corre el riesgo de ser sólo un negocio, donde la excelencia de la educación está concebida para perpetuar la desigualdad, donde la formación tiene un fin puramente laboral y además no lo cumple, donde los que estudian no necesariamente terminan siendo los más capaces de sobrevivir? ¿Cómo convertir la educación en un camino hacia la plenitud de los individuos y de las comunidades?

Inquietudes como las de Ospina no han sido atendidas con la seriedad que se merecen, por lo que se han consolidado las ofertas de modelos ilegales que, en el caso de la narcocultura, se instalaron ante la resistencia del modelo educativo a mirar los contextos antes que las cifras y los seres humanos antes que los trabajadores.

Es necesario preguntarse por qué razón algunos sectores de la academia en Colombia no han respondido con creatividad, incidencia e impacto a un proyecto educativo planificado y consensuado. Por el contrario, esta pregunta sí fue capitalizada por los medios masivos de comunicación, los cuales comprendieron la situación y la oportunidad histórica de hacer una puesta en escena en la que el narcotráfico es representado desde su dimensión criminal, pero con un margen de justificación frente a la ausencia e incapacidad de la escuela para resistir 
a las tentaciones del dinero y al reconocimiento social a corto plazo, similares ofertas de la educación, pero a largo plazo.

El siguiente apartado señala cómo la ficción televisiva se volcó al narcotráfico - en el momento en que lo identificó como un relator de buena parte de nuestra vida social, después de la década del noventay a la sombra de Pablo Escobar como el hombre sin oportunidades que logró salir adelante, ayudar a los suyos, desafiar al Estado y corromper buena parte de sus estructuras y funcionarios. El hijo mayor de Escobar, en su intento de justificar las acciones de su padre, culpa al sistema educativo de lo sucedido con su padre:

Mi padre hizo dos intentos por ingresar a la universidad, fue un hombre que intentó estudiar Abogacía y Periodismo, pero nunca fue aceptado, porque Colombia es restrictiva a la hora de ofrecer posibilidades a una educación superior.

[...] ¿cómo hubiese cambiado la historia de mi país si a mi padre se le hubiese dado la oportunidad de educarse?, creo que hubiera encontrado alternativas muy diferentes a las de la violencia para subsistir y para satisfacer su propia ambición (Carmona, 2013).

El legado de un narcotraficante que no pasó por la escuela refuerza el mito del personaje que genera odios y amores y se revalida con el triste ejemplo — no generalizable — de científicos que dejan el país ante la falta de oportunidades, profesionales desempleados y noticias diarias de otros profesionales al servicio de la corrupción o de la erosión de los recursos públicos. Ante la imposibilidad de la educación para responder al desespero por el progreso, el eje temático permitiría a las ficciones televisivas, desde su primer capítulo, justificar el origen y la legitimación del narcotráfico.

\section{La escuela en el salón y la narcocultura en la calle}

Las narcoseries no se han concentrado en revelar la responsabilidad de las élites económicas y políticas. Por el contrario, en una primera etapa, estas ficciones mostraron una dimensión no desconocida del narcotráfico: la efectividad de sus métodos y la imposición de sus métodos 
violentos, con una red de actores que, como una empresa, participan en la producción, distribución y comercialización de drogas ilícitas.

Luego, el éxito comercial de estas ficciones dio a los realizadores audiovisuales la confianza de realizar historias que, de manera indirecta, tocaran las fibras de algunos grupos de interés. En su gran mayoría, los relatos se concentraron en ahondar la penetración del narcotráfico como una subcultura que bebe de los valores del colombiano promedio - desconfiado de las instituciones, poco tolerante al pensamiento alternativo y apático a la movilidad social_ (Rodríguez-Raga y Seligson, 2007) y actúa de manera diferenciada en cada una de las capas sociales, sin importar el nivel educativo que ostenten.

Los ricos aceptan el dinero, pero no los gustos del narco, aunque terminan siendo muy parecidos; esto explicaría las similitudes entre las estéticas del narcotraficante y algunos sectores de las élites económicas en Colombia (Faciolince, citado en Rincón, 2009, pp. 150-151). La clase media trabaja en los oficios en los que se requieren profesionales para "modernizar" el negocio, entre los que se destacan, por lo menos dentro de las series, abogados, contadores, ingenieros, médicos, comunicadores sociales y políticos, entre otros. Los más pobres serán proveedores de violencia, oficios no calificados, sexo y servicios de mensajería y encubrimiento. Aquí puede verse una auténtica pirámide social que poco difiere de la predicada por el mundo de la legalidad.

La respuesta frente a estas propuestas ha variado de posiciones que ensalzan las series como fiscalizadoras de la realidad hasta posiciones moralistas que llaman a apagar el televisor. Las dos posiciones son respetables, pero prestan un flaco servicio a la discusión, pues no es tan saludable dejar a la empresa privada de la información la construcción de la memoria colectiva, como también es absurdo pensar que en la revolución de las comunicaciones el televisor o el computador dejarán de ser los aparatos preferidos en las familias.

En cambio, se proponen algunas puntadas para avanzar en las dinámicas que hacen posible el impacto y la consolidación de las representaciones mediáticas de estas series en su objetivo de pensar 
el narcomundo y su capacidad de adaptación a los cambios sociales, contrario al anquilosado sistema educativo, urgido de incorporar este tipo de reflexiones en procura de ciudadanos críticos con su entorno y con sus medios de comunicación.

\section{Progresar, sí. ¿Pero cómo? Las ambigüedades de los seriados}

Los canales de televisión recorren tres etapas cuando promocionan los seriados sobre el narcotráfico. En una primera fase venden la ficción como una historia basada en la vida real (estrategia que justifica las licencias que la ficción utiliza para disimular los vacíos y las imprecisiones históricas de las series). En la segunda, cuando la serie genera polémica, presentan un documental o emiten comerciales de responsabilidad social que resaltan lo malo del narcotráfico y la necesidad de no hacerle caso a las situaciones y mensajes de la serie. En la tercera, muestran el final infeliz de los protagonistas, a modo de moraleja con algunos condimentos de culpa religiosa.

A pesar de las buenas intenciones que puedan tener los productores y realizadores de este tipo de series, estas tres etapas son insuficientes o no reflejan la apuesta narrativa manejada en las producciones. Si bien el producto mediático apunta a presentar al narcotráfico como un modelo ilegal, en los primeros capítulos se muestra que es una forma de vida que se puede justificar ante la indolencia de las estructuras estatales y la permisividad social.

Lo que causa curiosidad es la coincidencia cuando representan la inevitabilidad del personaje para entrar en el mundo del narcotráfico. En ninguna de las series la escuela tiene voz para defenderse y evitar el destino de los protagonistas y, como sucede en el imaginario convencional, se presenta como un espacio tedioso o dominado por los actores ilegales que, de manera paradójica, vigilan que no enseñen cosas distintas a las que ya están establecidas para consolidar así una cultura del miedo a la diferencia y al diálogo entre iguales (Lizarralde, 2012). Se retratará esta situación con tres series que presentan el siguiente esquema en la emisión de sus primeros capítulos: 


\section{Esquema 1. Apuestas narrativas de las series}

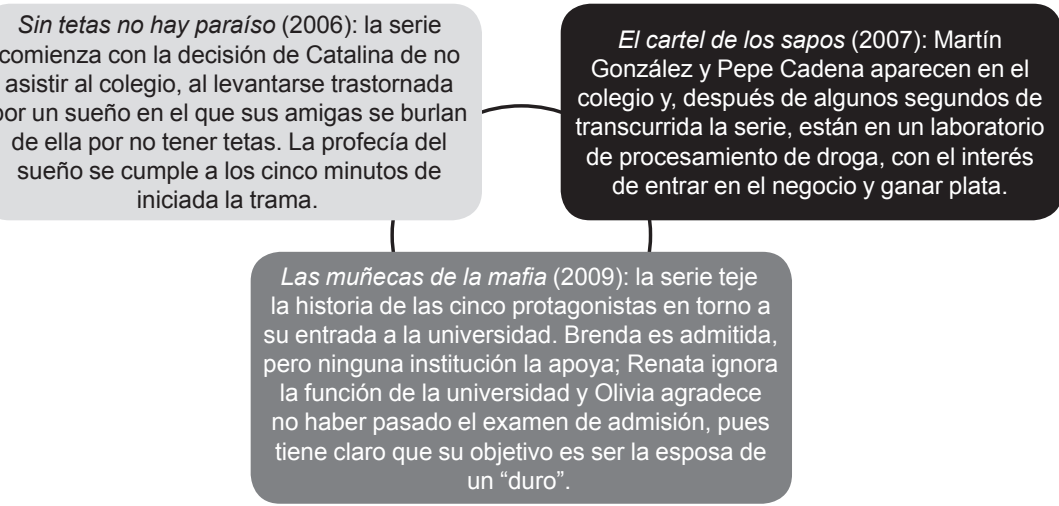

Fuente: elaboración propia.

\section{Sin tetas no hay paraíso: la escuela que no se manifiesta}

En el caso del seriado Sin tetas no hay paraíso, el libretista nos ubica en un barrio marginal de Pereira, con niñas menores de edad en condiciones no extremas, pero sí angustiosas, de pobreza material. En el caso de Catalina, se trata de una familia que no tiene papá. Ella comparte la habitación con su hermano mayor (Byron) y tiene una mamá sacrificada (Ilda) que debe luchar día a día para obtener el pan.

De entrada el televidente podría justificar la decisión de Catalina de no querer estudiar, pues la rodea la marginalidad, la pobreza y la exclusión. Todos estos son elementos - innecesarios, aunque suficientes - para poner a la educación como un espacio secundario en la vida de personas que todavía no han solucionado sus problemas materiales y que deben asistir a clases que hablan de otros mundos.

La hipotética identificación del televidente con el personaje se va fortaleciendo cuando Catalina sale a la calle y ve que llega el Titi, quien representa la antítesis de la condición social de ella. Es un mafioso, famoso (en el barrio), rico y carismático. Puede ser justificable que la operación mental de Catalina sea comparar el largo plazo de la educación frente a la inmediatez que le ofrece la aparición del Titi. 
Esta escena será acentuada por su amiga Jessica (la Diabla), quien reafirma la importancia del Titi en el barrio, pues pasó de ser un hombre normal a un "duro" reconocido por la comunidad. Catalina admite el estatus del Titi y trata de posar — en una especie de feria de ganadopara ser seleccionada y pasar un fin de semana en el que debe tener relaciones sexuales a cambio de dinero y regalos (ropa, celular, carro, apartamento), que se satiriza con una música festiva con la que Paola (una de las amigas de Catalina) le enseña cómo lucir para ser deseada por los mafiosos.

Catalina es rechazada por no tener tetas y esto acrecentará su angustia al ver que sus amigas de barrio comienzan a escapar de la marginalidad. Ella se va quedando sola y pasa un fin de semana haciendo ejercicio para distraerse y mantenerse en forma, mientras consigue el dinero para operarse los senos (según las recomendaciones de Jessica).

El concepto del fin de semana tiene un fuerte impacto para Catalina. Son días de pasarla bien y habría que investigar más a fondo las diferencias entre un fin de semana de pueblo y uno de ciudad, incluso en los grados de diferenciación en los modos de expresión rurales y urbanos del narcomundo. Jessica confirma que en esos días se come y "se pasa rico" con los narcos, quienes se caracterizan por presentarse como mecenas y ser propietarios de fincas, carros, piscinas, drogas y licor. Catalina valida la afirmación del fin de semana aburrido cuando dice que las envidia y expresa el hastío que le produce comer fríjoles (comida típica de Pereira, ciudad donde se desarrolla la novela).

La frustración de Catalina será capitalizada en el libreto con el argumento del Titi, quien, luego de escoger a Paola, le pregunta qué está haciendo. Ella contesta que está estudiando (sin saberse con claridad qué estudiaba), a lo que el Titi responde: "Para qué se pone a estudiar, si todo lo que he conseguido yo, lo he hecho sin estudiar". Paola no opone resistencia y le da la razón al Titi, pero más allá de esto, se sugiere cómo el narcotráfico se presenta como una alternativa cortoplacista y arriesgada, pero viable, efectiva y comprobable para obtener el ascenso económico que con la educación se tarda años en conseguir. 
Como un remedio, que termina siendo peor que la enfermedad, Albeiro (novio de Catalina) intenta ser la fuerza moralizante del dramatizado, al tratar de conducir a Catalina por "el camino del bien". De nuevo, una nueva justificación aparece para tratar de ponernos del lado de Catalina y darle la razón en su deseo de progresar por vías distintas a las débiles racionalidades de quienes intentan conducirla por "el camino del bien".

Albeiro es un hombre bueno y noble, pero sin ambiciones. Si damos una mirada desde la óptica del progreso capitalista, se podría plantear que es un tanto conformista y, sobre todo, machista, pues le dice a Catalina que él es su proveedor y que ella solo debe preocuparse por estudiar.

A Catalina no le convence el discurso y empieza a cuestionar la capacidad de Albeiro para suplir sus requerimientos y el conformismo de este al esperar que el amor sea suficiente: "Con un par de siliconas yo puedo cambiar todo mi mundo, todo lo que tengo a mi alrededor, pero usted con el amor que me tiene, usted no puede cambiar nada".

Catalina seguirá angustiada en el primer capítulo, pues el libretista se encarga de llevar las condiciones psicológicas al límite, para que la decisión final sea optar por el progreso que ofrece el narcomundo. Dos escenas serán clave: ver a sus amigas cuando llegan con muchos paquetes (ropa y perfumes), sonrientes y relajadas y una discusión con su hermano Byron, quien la increpa porque se levanta temprano a hacer ejercicio y la fastidia al decirle que consiga un marrano que mantenga a la familia o que se dedique a estudiar para que sea alguien en la vida.

La recriminación de Byron a su hermana, al parecer inofensiva, se estructura con el fin de reafirmar que "ser alguien en la vida", expresión ambivalente y objeto de múltiples discusiones en nuestras formas de vivir y pensar, se traduce en ser reconocido por tener dinero, demostrar superioridad y ser carismático con los más necesitados.

Este ideal se valida cuando Byron y Catalina discuten con Ilda acerca de la eficacia del estudio como sinónimo de progreso. Las posturas de 
Catalina y Byron (quien homologa el bachillerato) son contundentes, pues todas las personas a quienes nombran, estudiaron y no lograron los objetivos que se suponen alcanzables con la educación.

El silencio de Ilda es terminante (un elemento más de justificación y de inevitabilidad por la opción del narcomundo) y se refuerza cuando Byron le comunica que no va a estudiar más. Dice que consiguió un trabajo como limpiador de vidrios (en realidad es sicario) y acalla el cuestionamiento de su madre al entregarle dinero. La decisión de Byron no deja de referirse a la educación cuando se presenta ante el jefe de los sicarios, quien le dice que hay un trabajo por el que están pagando 50 millones: "Ese dinero no lo botan en la puerta de un colegio".

Llama la atención que en los primeros capítulos no aparece una voz que intente convencer a Catalina y Byron de la importancia del colegio para la formación personal. Presenciamos una escuela muda, sin orientaciones, sin voz; no se puede saber con certeza si estos factores son manejados con o sin intencionalidad, pero sí configuran una forma muy particular en la que la educación parece no ofrecer mucha resistencia.

Incluso hay una burla a la escuela y a su papel de orientador social, cuando Jessica busca a Catalina para decirle que un nuevo mafioso ha llegado y que quizá tenga oportunidad de acostarse con él y así obtener la financiación para la operación de las tetas. Para conseguir el permiso de Ilda, Catalina inventa que va a ir con Jessica a estudiar con el profesor de Biología. Es una historia absurda, no tanto porque la diga Catalina, sino porque la cree su mamá, quien, en una aparente ingenuidad, ve que Catalina y Jessica se suben a un carro, pero no concibe que un profesor de Biología cuente con el dinero para mantener un carro tan lujoso.

El clímax de la burla, en un principio argumentada por el Titi, será ingeniosamente complementada por los personajes ajenos al mundo mafioso. En otro acto de simplicidad, Albeiro e Ilda hablan sobre la actividad de Catalina con el profesor de Biología. Albeiro exige a 
Catalina que estudie, pero él no lo hace y legitima que estudiar "es una mamera" y que lo que se aprende sirve poco. La defensa de Ilda - como representante del estudio para el progreso- es muy débil, pues se limita a soltar frases a modo de moraleja.

En la única escena en la escuela, Catalina y Jessica dialogan ante un escenario mudo, descontextualizado, permisivo y que pasa por una excusa escenográfica que podría aceptarse en otras circunstancias. En este caso abre interrogantes sobre la pasividad de un espacio que es el eje central de los primeros capítulos de la serie.

La serie deja la defensa de la educación en las buenas, pero maleables, intenciones de Ilda. Mientras ellos van adquiriendo argumentos que se ven reflejados en la serie, Ilda solo se ve apoyada por frases débiles y de cajón sobre una escuela que, dentro de la serie, nunca habla y de la que dice de modo simplista: "Sirve para que los muchachos aprendan", situación que se exacerba cuando Byron llega a la casa con un celular e Ilda le pregunta dónde lo consiguió; Byron responde que es obvio que no lo consiguió estudiando. Esta respuesta genera la reacción de Albeiro, quien le advierte a Ilda sobre los malos pasos de su hijo, pero ella solo afirma: "Byron es así... de pronto por la falta de papá".

La serie construye los espacios necesarios para considerar que son pocos los repudios éticos al ingreso de lleno al mundo de los narcos y las siliconas. La escena en la que Catalina le dice a Jessica que se va a poner a estudiar (como un plan b y sin convicción), ante sus constantes fracasos, es fácilmente revertida cuando la Diabla le dice que hay una fiesta de muchos "traquetos" en donde aumentarán las oportunidades.

El plan b de Catalina pronto quedó en el olvido, cuando, en la fiesta que menciona Jessica, logró atraer y complacer sexualmente a un narcotraficante (Cardona), es decir, hizo bien su trabajo. Cardona le dice a Catalina que debe portarse bien para tener apartamento y carro. La escena es de particular impacto, pues nos cuestiona sobre los límites en el que las frases o decires del narcotraficante se distancian o más bien se acercan a los decires de nuestras prácticas sociales. 
Se plantea un nuevo nudo sobre el problema de las vías para conseguir las cosas. Cómo le contestamos a una Catalina en estos tiempos, cuando las transacciones económicas que circulan en público no siempre son tan legales y correctas como suele pensarse o cuando en el mundo del mercado también existe el discurso de "portarse bien" para tener apartamento y carro. Distanciados de estos derechos, hizo carrera un progreso que predica tener, desear, mirar, tocar, anhelar, sacrificar, pero es muy ambiguo al indicar los caminos individuales y colectivos más respetuosos y éticos para llegar a la tierra prometida, lo que da paso al imaginario consolidado de "un fin que justifica los medios".

\section{Las muñecas de la mafia: la universidad con y sin oportunidades, diferente, pero igual}

La protagonista (Brenda) tiene intenciones de estudiar y supera los exámenes de ingreso a la universidad, pero la serie se encarga de cerrarle los caminos: aparece la familia disfuncional (como sucedió con Catalina), cuando el papá gasta el dinero de la matrícula del semestre en alcohol, ante la mirada silenciosa de la mamá. Esto la obliga a conseguir un trabajo, que será más bien una representación del empleo informal o el denominado "rebusque".

Junto a Brenda, como un punto de comparación dentro de la serie, aparece Olivia, quien asume la posición de considerar el estudio "una pereza" y se propone "tener mucho billete y conseguirse un duro de verdad". Esta postura es cuestionada por Brenda, quien la increpa por su actitud interesada. Sin embargo, la situación económica de Brenda y el surgimiento de una amistad con Braulio (el narco de la serie) la llevan a una posición en la que reconoce a Braulio como "traqueto", mas se considera a salvo porque no forma parte de su organización, aunque disfruta de los fines de semana ofrecidos por su compinche. Poco o nada se sabe en capítulos posteriores sobre el interés de Brenda por retomar sus estudios. Es una acción que se lleva a modo de excusa en el primer capítulo, como para justificar el contexto que llevó a Brenda a su triste destino, pero carece de sustento en el desarrollo de la trama.

En cambio, Olivia se casa con el duro (Braulio) y en una ocasión le dice a Brenda "se lo gané". Con ello demuestra la consecución de su 
objetivo frente al fracaso académico de Brenda, quien terminó sin educación y sin narco (algo muy parecido a lo que le sucedió a Catalina en Sin tetas no bay paraíso). Al final, a modo de modesta reivindicación, el libretista representa el triunfo de Brenda sobre Olivia con la vieja estrategia del embarazo como argumento para la purificación de las mujeres. Mientras Olivia es apresada y llora por su destino, Brenda queda eximida de posibles acusaciones por complicidad, incluso se salva de ser asesinada, porque se supone que tener un hijo le da un manto de inmunidad por el respeto que supone la figura de la madre no solo para los narcos, sino para la sociedad que vive en el mundo "legal". La serie intenta mostrar que hay posibilidad de la reivindicación, pero su estrategia no convence, pues lo que se demuestra es el fracaso de Brenda para acceder a las oportunidades de la legalidad y la ilegalidad; tiene que volver a una situación de exclusión social, que vive más por obligación que por convicción.

Un párrafo aparte merece Pamela (otra de las protagonistas), quien aparece en el colegio y luego en la universidad (otra vez es un escenario de justificación para el desarrollo de la escena, pero en ningún momento para articular la institución con el entramado de la historia). Para ella, la universidad es un espacio de escape, por lo que desaparece de manera justificable, pero poco sustentada. Esto se evidencia en un diálogo entre Pamela y Asdrúbal (narco) después de tener relaciones sexuales:

- Pamela: ¿Me lleva a la universidad, por fa?

- Asdrúbal: ¿A la universidad? Uy no, qué pereza. Más bien quedémonos aquí que Norman nos invitó a almorzar.

Tal vez por miedo, ella obedece la sugerencia de Asdrúbal, pues había quedado desprotegida al enterarse de que su papá (piloto) trabajaba transportando droga.

\section{El cartel de los sapos: educación y minoría de edad}

Es interesante identificar aquí la vinculación de los menores de edad al negocio. Al realizar una revisión de las polémicas generadas por la serie, este aspecto no tuvo mayor atención. Los dos protagonistas narran sus hechos en el colegio cuando apenas tienen 15 años 
(de nuevo, la escuela muda) y con un profesor que habla sin tener la atención de sus estudiantes y con una ironía que se resiste a lo implícito: el profesor está en una clase de sintaxis explicando el sujeto, verbo y predicado poniendo como ejemplo la oración "La paz es necesaria".

Los libretistas no pintan un panorama triste e inevitable (como en los casos de Catalina y Brenda), sino un escenario pintoresco donde, pese a las delaciones y traiciones, se deja la idea de una red de trabajo que funciona de manera eficiente y eficaz, en la que la ley del más fuerte prevalece en un sistema de ascensos, con el triunfo de los más astutos y prudentes.

En este punto, el recurso será más estratégico y conectado con el imaginario del joven. Martín y Pepe (protagonistas) ingresan al negocio por dinero, pero también por cierto grado de excitación que les produce formar parte de algo "que genera adrenalina y necesidad de reconocimiento". ¿Dónde están las instituciones legales para brindar otros espacios de diversión y ocio?

Otra coincidencia de las series está en el punto de trabajar con jóvenes, es decir, con un sector poblacional inquieto por descubrir las oportunidades que le brinda la vida, allí donde se necesita juventud y riesgo para obtener réditos (Secretaría de Seguridad Pública de México, 2010). Por eso, en las series hay referentes con edad avanzada, para que sean vistos con admiración, respeto y miedo y para reforzar la idea de un modelo que acata las jerarquías y que, en el momento en que los líderes son capturados o mueren de manera violenta, se convierten en un mito digno de emular o de vengar (Ovalle, 2010).

Películas como Rodrigo D y La vendedoras de rosas muestran el exterminio sistemático de la juventud y la inevitabilidad de su prematura muerte (Salazar, 1990). A diferencia de esto, El cartel de los sapos presenta la posibilidad de un narcotraficante para sobrevivir en medio de las traiciones, las desconfianzas y los asuntos empresariales que se resuelven en la trama (con una expresión abierta de violencia física). Un narco que escribe libretos -Andrés López, alias Florecita, para El cartel de los sapos - y se toma fotos con el jet set criollo envía un mensaje dife- 
rente, aunque Caracol invierta algunos millones en poner a los actores a decir que ser narco es malo y que el negocio no paga.

\section{Consideraciones finales}

A pesar de la televisión y sus ficciones exacerbadas, no se puede dirigir toda la culpa a la ausencia de una política educativa que integre de manera novedosa a los jóvenes de este país (Amador y Gilmar, 2010). Es imperativo que otros sectores de la sociedad dejen de asignarle todo el peso a la escuela como responsable de los futuros ciudadanos. Familia, casa, barrio y colectivos, entre otras formas de organización social, deben ponerse la camiseta - en referencia a un término coloquial que expresa el trabajo colectivo-. Es parte de otro artículo, pero ya hay experiencias que han tomado conciencia del problema y están adelantando loables iniciativas que advierten sobre la permisividad de los estilos de vida inspirados en las herencias del narcotráfico.

La escuela debe adoptar estrategias que la lleven más allá de ser un simple escenario de transmisión de conocimientos y la posicionen como un espacio en donde se encuentren alternativas que propicien reflexión y transformación de nuestros contextos de indiferencia y exclusión (Jacinto, 2000). En caso contrario, estas historias permanecerán como un tema rentable para los medios y un relato en el que los jóvenes serán representados como la población que más accede a las representaciones siempre al límite, abiertamente ilegales, pero legítimas, al momento de ser interiorizadas como una opción de vida riesgosa y válida si se quiere sobrevivir en un mundo dominado por el intercambio de bienes.

En este sentido, las series refuerzan la validez de los personajes (jóvenes) principales a aceptar la necesidad de crecer al lado de personajes que no solo están en el mundo ilegal, sino que tienen más experiencia y que fungen como sus tutores. Catalina con el Titi, Brenda y Olivia con Braulio, Pamela con Asdrúbal y la pareja Martín-Pepe con Óscar Cadena logran su proceso de maduración y reafirman el amor o respeto por su mentor. Esta situación es retratada con ligereza en las series; sin embargo, debería generar una reflexión amplia y consensuada de distintos sectores sociales que tienen la obligación de buscar fórmulas 
creativas para evitar prohibiciones y más bien proponer prácticas que estimulen el quiebre del imaginario de la vida legítima que ha edificado la narcocultura.

La tarea es titánica, pues se trata de movilizar imaginarios, estereotipos, prejuicios, opiniones y creencias, pero la magnitud de la labor no significa que no se deba llevar a cabo, pues la televisión es un medio todavía poderoso e influyente en distintos sectores de nuestra sociedad. No influir en ella es cometer el error estratégico de perder un aliado en la transformación cultural y social que se requiere para buscar puntos de encuentro con los modelos educativos que se piensan en Colombia y el mundo.

Las narcoficciones se resisten a perder la influencia y retroalimentación de colombianas y colombianos que ven en su modelo económico y social una vía para el ascenso y reconocimiento social o un formato de entretenimiento que no merece mayor reflexión y análisis sobre los valores que nos definen como individuos, sociedad y país.

No se puede dar espacio a las conclusiones apocalípticas, porque estas otorgan más fuerza al narcomundo, que cada vez está más lejos de desaparecer de nuestras dinámicas socioculturales. La educación es un motor fundamental para el desarrollo humano, pero falta salir del lugar cómodo de los contenidos y las metodologías sencillas de calificar, para tratar de imprimir una docencia apasionada con la vida de los estudiantes y en el que los problemas de nuestro país sean expuestos de manera abierta y franca, porque los medios no tienen reparos en hacer adaptaciones, en buena parte sesgadas e indiferentes a la pluralidad de voces.

Uno de estos problemas a debatir en la escuela es la incidencia del narcomundo en nuestro estilo de vida. Nadie discute que la historia del siglo XIX de Europa sea importante, pero tal vez este tipo de metodologías podrían hacer un esfuerzo por establecer nexos entre la historia impuesta por los lineamientos del Ministerio de Educación y las relaciones que se establecen en la vida cotidiana, difíciles de identificar, complejas de describir y necesarias de relatar en el aula de clase. 
Puede ser un punto polémico, mas la narcocultura sobrevive gracias a su creatividad para insertarse con estrategias diferenciadas entre los actores sociales. Para responder a este desafío, no se puede seguir en el plano de la denuncia y el moralismo. Es urgente salirse un poco de la guía educativa y arriesgarse a ir más allá de clases que siguen el conducto regular de la transmisión de conocimientos, muchas veces abstractos y asumidos como un recetario para superar unos créditos académicos.

El experto en educación Ken Robinson (2011) acierta al afirmar que los maestros matamos la creatividad, que la imaginación queda neutralizada y que los diversos talentos de los estudiantes son olvidados y marginados por la imposición de conceptos, notas y regaños. A esta situación, Robinson añade la triste anécdota de contar que, cuando asiste a una fiesta y dice que es educador, las personas lo miran con cara de tragedia y pesar, situación que lo lleva a reflexionar sobre los roles del maestro en su interacción con los estudiantes y cómo, a pesar del acuerdo generalizado sobre la importancia de la educación, existe todavía un compromiso exiguo de actores influyentes en el terreno político y económico en el momento de fortalecer los aciertos y prevenir los errores de la escuela en su función orientadora de seres humanos.

Ahí está la ruptura del país con la universidad. Los papás mandan a los niños a la escuela, porque la presión social lo dice, pero no porque están convencidos. Ser educador en Colombia —es una investigación en mora de hacerse - es visto como un empleo secundario de aquellos que no lograron acomodarse en la vida profesional (imaginario que es reforzado cuando doctores formados en el exterior llegan a Colombia y se ven frustrados ante la falta de oportunidades para la investigación). Al no tener más oportunidades, deciden tomar horas de clase por la obligación de trabajar, lo que genera frustración, pues aunque ese profesional tenga una excelente preparación, se decepciona cuando los estudiantes no responden a sus expectativas.

En Finlandia, Singapur e Inglaterra ser docente es una profesión respetada. En Colombia es todo lo contrario. Desde los hogares criamos a nuestros hijos con la idea de que la escuela es como lo dice el docu- 
mental de La educación probibida: "Un parqueadero para niños", donde el profesor "tiene" que dar conocimientos para que algún día pueda ingresar al sistema laboral.

Si se analizan a profundidad los planteamientos de Robinson, su crítica no está dirigida a las escuelas como limitantes de la creatividad, sino a la manera como se ha concebido el concepto de estudiante, maestro y pedagogía. El problema no se soluciona acabando jardines, colegios y universidades. La transformación comienza desde los espacios cotidianos y la academia debe dejar de ser vista como un espacio donde los padres de familia dejan a sus hijos mientras van a trabajar, para ser un laboratorio de prácticas democráticas que tengan impacto para resistir con creatividad y sin violencia a las ofertas de una narcocultura que atenta contra la construcción de un proyecto colectivo de Nación, donde impere el respeto por el otro.

Una escuela que ignora, subestima/sobreestima el poder y la influencia de los medios de comunicación, el narcomundo y los sueños, las expectativas y las frustraciones de los jóvenes está condenada no solo a tener posiciones marginales en las pruebas mundiales de educación (OECD, 2012), sino a la desigualdad económica, la injusticia social y la corrupción política.

Asumir el reto desde la educación podría contribuir a disminuir los impactos del narcomundo y sus ficciones. No se puede figurar que se produzca una serie sobre la vida ejemplar de un maestro, pero sí formar una teleaudiencia de jóvenes críticos frente a las producciones audiovisuales. Tampoco se espera que cambien las políticas prohibicionistas, pero sí asumir la narcocultura como un tema de discusión nacional y qué mejor escenario que el aula de clase, ese espacio donde confluyen jóvenes con caras de aburrimiento, aunque con la expectativa de tener alguna interpretación de la realidad que viven.

Tal vez los hombres y las mujeres que se dedican a transformar nuestras realidades alguna vez contaron con un maestro que le dio sentido al mundo que les rodeaba. Catalina, Brenda, Pamela, Martín y Pepe son personajes diseñados con ánimo de lucro, mas tal vez sean la 
representación de esos jóvenes que nunca encontraron una voz que no los llamarán por su apellido o por el código que los identificaba.

\section{Referencias bibliográficas}

Amador, J., y Gilmar, C. (2010). Emergencias de la memoria. Dos estudios sobre la infancia, la escuela y la violencia. Bogotá: Fondo de publicaciones Universidad Distrital Francisco José de Caldas.

Brito, Z. (2008). Educación popular, cultura e identidad desde la perspectiva de Paulo Freire. En M. Godotti, M. Gómez, J. Mafra, A. Fernandes (comps.), Paulo Freire. Contribuciones para la pedagogía (pp. 29-45). Buenos Aires: Clacso.

Buenaventura, N. (1995). La importancia de hablar mierda o los hilos invisibles del tejido social. Bogotá: Magisterio.

Cajiao, F. (2004). La concertación de la educación en Colombia. Revista Iberoamericana de Educación, (34), 31-47.

Carmona, R. (2013, 10 de febrero). Hijo de Pablo Escobar: En la educación hay alternativas para no caer en la violencia. Su noticiero.com. Recuperado de http://sunoticiero.com/index.php/internacional-not/2478-hablahijo-de-pablo-escobar-no-soy-narcotraficante-porque-conoci-que-enla-educacion-y-el-dialogo-hay-alternativas-para-no-caer-en-la-violencia Castro-Gómez, S. (2000). Teoría tradicional y teoría crítica de la cultura. En Autor (ed.), La reestructuración de las ciencias sociales en América Latina (pp. 93-108). Bogotá: Instituto Pensar.

Chavarría, M. (2012). No todo lo que se dice Montessori lo es: decodificación de elementos esenciales en un mundo globalizado. Actualidades Investigativas en Educación, 12 (2), 1-38.

Costa, A., y Domenech, G. (2002). Distintas lecturas epistemológicas en tecnología y su incidencia en la educación. Enseñanza de las ciencias, 20 (1), 159-165.

De Vroede, M. (1989). Antecedentes históricos de la formación del profesorado de Educación Básica en los países de la comunidad europea. Revista Interuniversitaria de Formación del Profesorado, (5), 61-73.

Doin, G. (2012). Reseña del documental La educación prohibida: nuevos paradigmas educativos en América Latina. Polis, 11 (33), 485-489.

Duncan, G. (2006). Los señores de la guerra. De paramilitares, mafiososy autodefensas en Colombia. Bogotá: Planeta. 
Foucault, M. (2001). Defender la sociedad. México D. F.: Fondo de Cultura Económica.

Foucault, M. (2009). Vigilar y castigar: nacimiento de la prisión. México D. F.: Siglo XXI.

Frankl, V. (s. f.). Una fábrica de monstruos educadísimos. Recuperado de http:// goo.gl/Nt1lLc

Friedman, M. (1992). Libertad de elegir: hacia un nuevo liberalismo económico. Bogotá: Grijalbo.

Gambetta, D. (2007). La mafia siciliana: el negocio de la protección privada. México D. F.: Fondo de Cultura Económica.

Garay, L. (dir.) (2008). La captura y reconfiguración cooptada del Estado en Colombia. Bogotá: Método, Avina, Transparencia por Colombia.

García, M., y Quiroz, L. (2011). Apartheid educativo: educación, desigualdad e inmovilidad social en Bogotá. Economía Institucional, 13 (25), 137-162.

Gómez, D., Ailen, E., Blanc, F., y Moreno, F. (productores) y Doin, G. (director. (2012). La educación probibida (Documental). Argentina: Eulam Producciones.

González, F., Bolívar, I., y Vásquez, T. (2002). Violencia política en Colombia: de la nación fragmentada a la construcción del Estado. Bogotá: Cinep.

Horkheimer, M. (1983). El Estado autoritario. Bogotá: Crearte.

Jacinto, C. (2000). Los jóvenes, la educación y el trabajo en América Latina. Nuevos temas, debates y dilemas. Buenos Aires: Cinterfor.

Jaramillo, N. (2006). Clientelismo y poder. Consideración crítica sobre el papel de la reflexión del poder en el estudio del clientelismo en Colombia. En Investigaciones en Construcción: vol. 5. Bogotá: Universidad Nacional de Colombia.

Jaramillo, R. (1998). Colombia: la modernidad postergada. Bogotá: Temis.

Lizarralde, M. (2012). La escuela y la guerra, las memorias entre el miedo y el silencio. Praxis Pedagógica, 13, 90-103.

Martínez, M. (1999). El enfoque sociocultural en el estudio del desarrollo y la educación. Revista Electrónica de Investigación Educativa, 1 (1), 16-37.

Ministerio de Educación Nacional. (2012). Índice de progreso de la educación superior. Bogotá: Ministerio de Educación Nacional.

Morin, E. (1984). Ciencia con conciencia. Madrid: Anthropos.

Múnera, A. (2008). El fracaso de la Nación: región, clase y raza en el Caribe colombiano (1717-1821). Bogotá: Planeta. 
Nussbaum, M. (2010). Sin fines de lucro: por qué la democracia necesita de las humanidades. Buenos Aires: Katz Editores.

OECD. (2012). Colombia. Student Performance (Pisa 2012). Recuperado de: http://gpseducation.oecd.org/CountryProfile?primaryCountry $=\mathrm{C}$ OL\&treshold $=10 \&$ topic $=$ PI

Orsini, G. (2007). Poligamia y contrabando: nociones de legalidad y legitimidad en la frontera Guajira, siglo XX. Bogotá: Universidad de los Andes.

Ospina, W. (septiembre, 2010). Preguntas para una nueva educación. Conferencia presentada en el Congreso Iberoamericano de Educación Metas 2021. Buenos Aires, Organización de Estados Americanos.

Ovalle, L. (2010). Narcotráfico y poder. Campo de lucha por la legitimidad. Athenea Digital, 17, 77-94.

Palacios, M. (2003). Entre la legitimidad y la violencia: Colombia 1875-1994. Bogotá: Norma.

Patiño, C. (2006). El origen depoder en Occidente: Estado, guerray orden internacional. Bogotá: Siglo del Hombre Editores.

Pizarro, E. (2011). Las FARC: (1949-2011). De guerrilla campesina a máquina de guerra. Bogotá: Norma.

Quiñones, B. (2011). Narcotráfico y ficción televisiva. Mujer y narcomundo: una mirada desde los estereotipos de mujer y la feminización de la pobreza. Bogotá: Instituto de Estudios Comunicación y Cultura, Universidad Nacional de Colombia.

Rincón, Ó. (2009). Narco.estética y narco.cultura en Narco.lombia. Revista Nueva Sociedad, (222), 147-163.

Ríos, C. (2010). Un acercamiento al concepto de formación en Gadamer. Educación y Pedagogía, (14-15), 13-35.

Robinson, K. (2011). Las escuelas matan la creatividad. Recuperado de: http:/ / www.youtube.com/watch?v=AW-bTuBA5rU

Rodríguez-Raga, J., y Seligson, M. (2007). Cultura politica de la democracia en Colombia. Bogotá: Observatorio de la Democracia, Universidad de los Andes, Barómetro de las Américas.

Salazar, A. (1990). No nacimos pa' semilla. Bogotá: Cinep.

Secretaría de Seguridad Pública de México. (2010). Jóvenes y narcocultura. México D. F.: Secretaría de Seguridad Pública.

Sennett, R. (2000). La corrosión del carácter: las consecuencias personales del trabajo en el nuevo capitalismo. Barcelona: Anagrama. 
Sopó, Á. (2007). El concepto hegeliano de formación. Una aproximación. Logos, (12), 39-47.

Thoumi, F. (2002). El imperio de la droga. Narcotráfico, economía y sociedad en Los Andes. Bogotá: Iepri.

Uribe, C. (1992). La mentalidad del colombiano: cultura y sociedad en el siglo XX. Bogotá: Alborada.

Vargas, R. (1999). Drogas, máscaras y juegos. Narcotráfico y conflicto armado en Colombia. Bogotá: Tercer Mundo Editores.

Vasco, C. (marzo, 2006). Siete retos de la educación colombiana para el perído 2006-2019. Serie de conferencias presentadas en Medellín, Universidad EAFIT. 